\title{
A Combined Experimental and Theoretical Electron Density Study of Intra- and Intermolecular Interactions in Thiourea $S, S$-Dioxide
}

\author{
Chi-Rung Lee, $*\left[\right.$ [b] Ting-Hua Tang, ${ }^{[a]}$ Likey Chen, ${ }^{[a]}$ and Yu Wang*[a]
}

\begin{abstract}
The thiourea $S, S$-dioxide molecule is recognized as a zwitterion with a high dipole moment and an unusually long $\mathrm{C}-\mathrm{S}$ bond. The molecule has a most interesting set of intermolecular interactions in the crystalline state-a relatively strong $\mathrm{O} \cdots \mathrm{H}-\mathrm{N}$ hydrogen bond and very weak intermolecular $\mathrm{C} \cdots \mathrm{S}$ and $\mathrm{N} \cdots \mathrm{O}$ interactions. The molecule has $C_{s}$ symmetry, and each oxygen atom is hydrogen-bonded to two hydrogen atoms with $\mathrm{O} \cdots \mathrm{H}-\mathrm{N}$ distances of 2.837 and $2.826 \AA$ and angles of 176.61 and $158.38^{\circ}$. The electron density distribution is obtained both from X-ray diffraction data at $110 \mathrm{~K}$ and from a periodic density functional theory (DFT) calculation. Bond characteriza-
\end{abstract}

\begin{abstract}
tion is made in terms of the analysis of topological properties. The covalent characters of the $\mathrm{C}-\mathrm{N}, \mathrm{N}-\mathrm{H}, \mathrm{C}-\mathrm{S}$, and $\mathrm{S}-\mathrm{O}$ bonds are apparent, and the agreement on the topological properties between experiment and theory is adequate. The features of the Laplacian distributions, bond paths, and atomic domains are comparable. In a systematic approach, DFT calculations are performed based on a monomer, a dimer, a heptamer, and a crystal to see the
\end{abstract}

Keywords: charge density • density functional calculations - hydrogen bonds - topological analysis - X-ray diffraction effect on the electron density distribution due to the intermolecular interactions. The dipole moment of the molecule is enhanced in the solid state. The typical values of $\rho_{\mathrm{b}}$ and $H_{\mathrm{b}}$ of the hydrogen bonds and weak intermolecular $\mathrm{C} \cdots \mathrm{S}$ and $\mathrm{N} \cdots \mathrm{O}$ interactions are given. All the interactions are verified by the location of the bond critical point and its associated topological properties. The isovalue surface of Laplacian charge density and the detailed atomic graph around each atomic site reveal the shape of the valence-shell charge concentration and provide a reasonable interpretation of the bonding of each atom.

\section{Introduction}

Intermolecular interactions, particularly hydrogen bonds, play a key role in molecular recognition in a wide range of chemical and biological systems. ${ }^{[1]}$ These interactions are almost ubiquitous in molecular crystals and biological molecules. For the hydrogen-bond interaction, studies that use the theory of atoms in molecules (AIM), ${ }^{[2]}$ based on both theoretical $^{[3-14]}$ and experimental ${ }^{[15-25]}$ electron densities, have drawn considerable interest recently. Different types of

[a] Prof. Y. Wang, Prof. T.-H. Tang, Dr. L. Chen

Department of Chemistry

National Taiwan University

Taipei 106, Taiwan (Republic of China)

Fax: (+886)-2-23636359

E-mail: yuwang@xtal.ch.ntu.edu.tw

[b] Prof. C.-R. Lee

Department of Chemical Engineering

Minghsin University of Science and Technology

Hsin-chu 304, Taiwan (Republic of China)

E-mail: crlee@mhit.edu.tw

Supporting information for this article is available on the WWW under http://www.chemeurj.org/ or from the author. hydrogen bonding and weak interactions have been studied to elucidate the nature of these interactions. The topological properties of the electron density distribution of both a molecule and a crystal are based on the gradient vector field of the electron density $\nabla \rho(\boldsymbol{r})$ and on the Laplacian distribution of the electron density $\nabla^{2} \rho(\boldsymbol{r})$. Several excellent reviews have been published ${ }^{[2,15,26-28]}$ on this subject. In the light of the AIM approach, experimental and theoretical research into the charge density distributions of many different types of chemical bond in organic, sulfur-containing compounds and metal complexe ${ }^{[29-32]}$ has been studied in terms of local charge concentration and local charge depletion of a Lewis acidbase concept. ${ }^{[2]}$ This general phenomenon has been well studied in many other kinds of interaction, such as the formation of hydrogen bonds, ${ }^{\left[{ }^{3-25]}\right.}$ the directional intermolecular interaction of $\mathrm{Cl}_{2}{ }^{[33]}$ and $\mathrm{S}_{4} \mathrm{~N}_{4}{ }^{[34,35]}$ in the solid state, and even the binding interaction in van der Waals dimers and a trimer, ${ }^{[36]}$ as well as the adsorption of molecules on a surface. ${ }^{[37]}$

The charge density, chemical bonding, and intermolecular interactions of urea and thiourea have all been extensively investigated..$^{[8,25,38-41]}$ It was reported ${ }^{[38]}$ that the observed planar geometries of guanidine and urea in the crystal form 
are probably due to hydrogen bonding. In a theoretical study, hydrogen-bonded aggregates of urea and thiourea were reported $^{[39]}$ to form chains and ribbons. The structure and charge density of the complex of thiourea with parabanic acid were studied at room temperature, ${ }^{[25]}$ and two $\mathrm{N}-\mathrm{H} \cdots \mathrm{S}$ and $\mathrm{N}-\mathrm{H} \cdots \mathrm{O}$ weak hydrogen-bonding interactions were located in the cyclic parabanic acid-thiourea dimer. A preliminary study was carried out for crystalline urea a decade ago with the ab initio approach. ${ }^{[40]}$ In a further study using the periodic Hartree-Fock (PHF) approach, ${ }^{[8]}$ with the geometry taken from the accurate neutron diffraction, ${ }^{[41]}$ two in-plane and two out-of-plane hydrogen bonds, as well as intramolecular interactions, were described in terms of the AIM theory in the crystal structure of urea. The topological properties associated with the bond critical points (BCPs) were investigated in the gas phase and the solid state, for the purpose of understanding changes in the properties due to changes in the packing environment, in other words, the crystal packing effect. It was found that, on going from molecule to crystal, both the $\left|H_{\mathrm{b}}\right|$ and $\rho_{\mathrm{b}}$ values increase for the $\mathrm{C}-\mathrm{N}$ bond, while these values decrease for all other bonds. ${ }^{[8]}$ This means that only the $\mathrm{C}-\mathrm{N}$ bond is strengthened, where an increase of $\pi$ character is induced by crystal packing. It is not often found that a carbonyl oxygen atom is involved in four hydrogen bonds, as in this case; the calculated sublimation energy was $91.21 \mathrm{~kJ} \mathrm{~mol}^{-1[8]}$ in comparison with the experimental value of

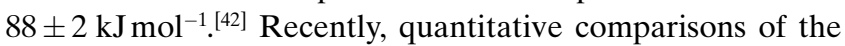
experimental and theoretical charge densities of urea were made. ${ }^{[43]}$ The intermolecular interaction energy in crystalline urea was calculated both from diffraction data and with the PHF approach by using a modified atom - atom approximation scheme; the calculated sublimation energy was $90 \mathrm{~kJ} \mathrm{~mol}^{-1}$, which is very close to the value of $96 \mathrm{~kJ} \mathrm{~mol}^{-1}$ obtained by experiment. ${ }^{[44]}$

The purpose of the present study is to investigate the intraand intermolecular interactions, particularly the hydrogen bonding, in a molecular crystal. Thiourea $S, S$-dioxide was chosen due to its zwitterionic character and its $\mathrm{C}-\mathrm{S}$ bond, which is the longest known (1.8592 $\AA$ ), to best of our knowledge. The extensive hydrogen-bond network throughout the crystal may well be the result of the high dipole moment of the molecule. The molecule is quite unique and, together with the previous knowledge about urea and thiourea, ${ }^{[8,25,38-44]}$ it is bound to give much insight into the intermolecular interactions. A systematic study concerning the intermolecular interactions of this molecule should be very interesting. According to our previous studies, the crystal structure $^{[45]}$ of this molecule is in space group Pnma. Each oxygen atom is involved in two hydrogen bonds similar to those in urea. A preliminary electron density study ${ }^{[46]}$ was made by single-crystal X-ray diffraction at $110 \mathrm{~K}$ and by a molecular-orbital calculation based on an isolated molecule. The agreement on the chemical bonding characterization between the experimental and theoretical results was adequate. ${ }^{[46]}$ The main interests of this work are, however, the hydrogen bonds and other weak intermolecular interactions. In order to understand the nature of such intermolecular interactions in this molecule in the solid state, theoretical charge densities are to be calculated systematically for the monomer, dimer, heptamer, and crystal. The effect on the chemical bonds due to molecular packing will be investigated in terms of the AIM theory.

\section{Results and Discussion}

Structure and multipole model: The molecular structure of thiourea $S, S$-dioxide with its atomic labeling and internal coordinates is depicted in Figure 1. The molecular symmetry is $C_{s}$, and two types of hydrogen bond exist in the crystal. In

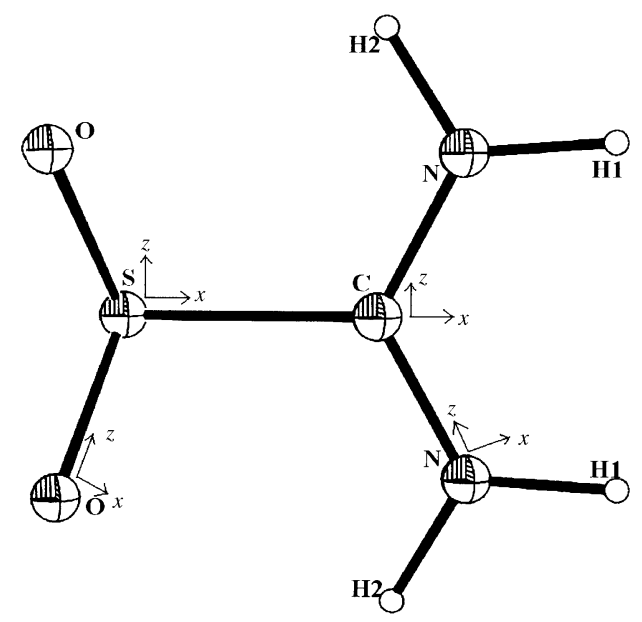

Figure 1. The molecular structure of thiourea $S, S$-dioxide with atomic labeling and internal coordinates.

the first, molecules are linked to each other through hydrogen bonds in pairs between the $\mathrm{N}-\mathrm{H} 1$ group and an $\mathrm{O}$ atom to form a "head-to-tail" type bond with an $\mathrm{O} \cdots \mathrm{H} 1-\mathrm{N}$ distance of $2.837 \AA$ and an angle of $176.61^{\circ}$ (Figure $2 \mathrm{a}, \mathrm{b}$ ). The other type of bond is between the $\mathrm{N}-\mathrm{H} 2$ group and a neighboring $\mathrm{O}$ atom with an $\mathrm{O} \cdots \mathrm{H} 2-\mathrm{N}$ distance of $2.826 \AA$ and an angle of $158.38^{\circ}$ (Figure $2 \mathrm{a}, \mathrm{b}$ ). Each $\mathrm{H}$ atom is involved in one type of hydrogen bond, but each $\mathrm{O}$ atom is involved in two hydrogen bonds. These two types of hydrogen bond form a zig-zag network and give rise to an infinite network of molecules throughout the crystal (Figure $2 \mathrm{a}, \mathrm{b}$ ). In addition, there are weak $\mathrm{C} \cdots \mathrm{S}$ and $\mathrm{N} \cdots \mathrm{O}$ interactions in the crystal as shown in Figure $2 \mathrm{c}$. The structural parameters are the same (within standard deviations) as those given in the previous work, ${ }^{[46]}$ where the deformation density maps based on the multipole model were also shown. In this work, multipole refinements are performed with an additional quadrupole term for the $\mathrm{H}$ atom and $\kappa^{\prime}$ for each atom. Parallel multipole refinements based on the structural amplitudes ( $F$ values) derived from a periodic density functional theory (PDFT) calculation are also carried out. The residual maps after the multipole refinements based on experimental structural amplitudes and the theoretically derived ones are displayed in Figures 3 a and $b$, respectively. The maps are essentially featureless. The agreement indices and the multipole coefficients from various refinements are qualitatively the same. Of course, the $U_{i j}$ values were set to zero for the model derived from the PDFT calculation. The list of parameters is given in the Supporting 


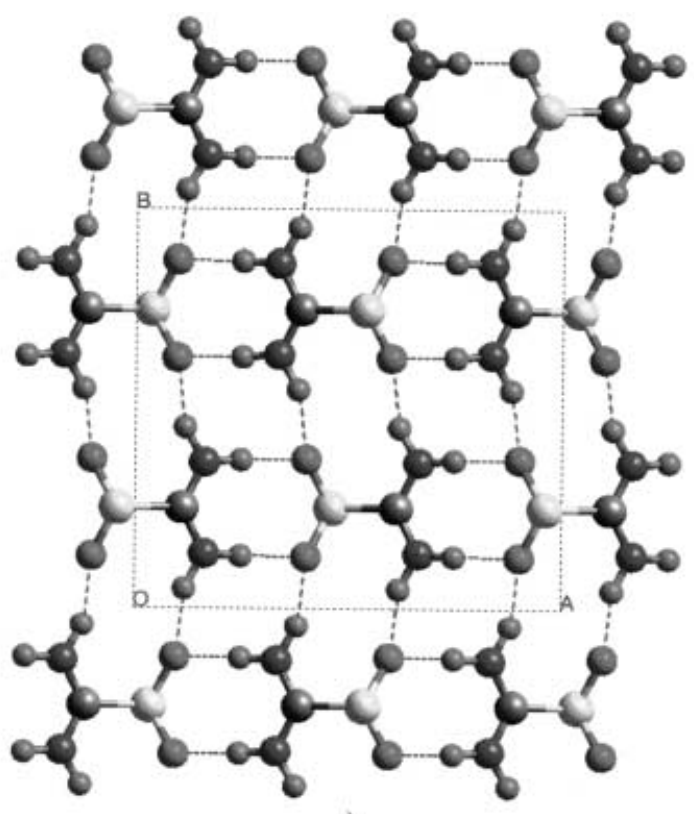

a)

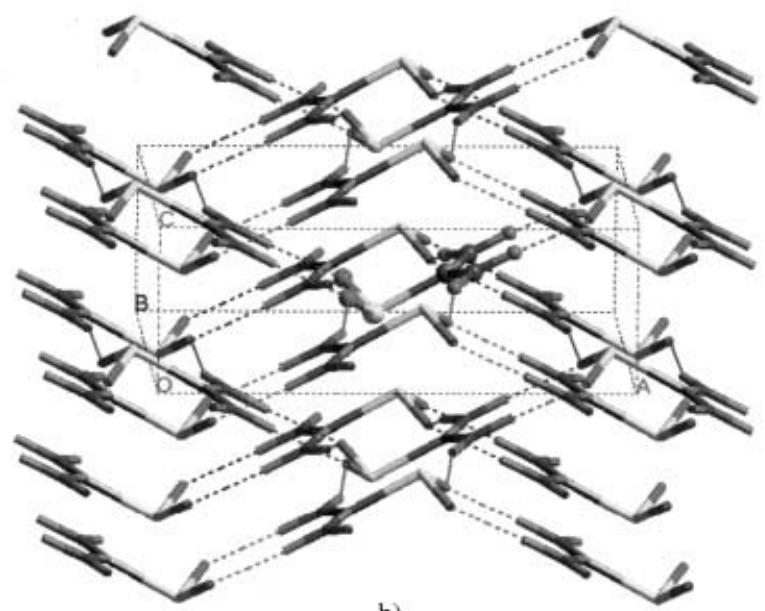

b)

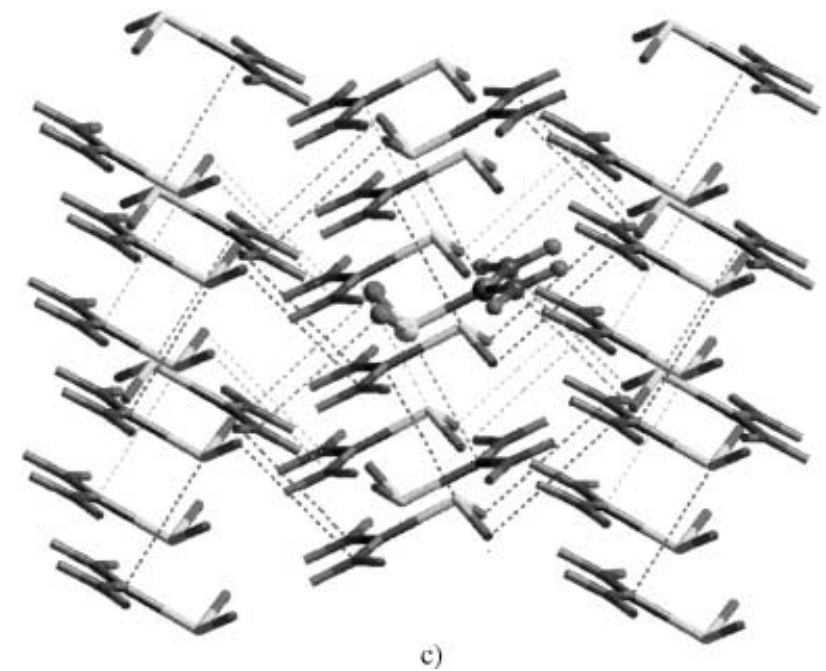

Figure 2. The intramolecular bonds (sticks) and intermolecular hydrogen bonds and weak interactions (dashed lines) in the crystal packing. a) Projection on the $a, b$ plane showing the hydrogen bonds, b) display of the in-plane and out-of-plane hydrogen bonds, c) depiction of the $\mathrm{C}-\mathrm{S}$ and $\mathrm{N}-\mathrm{O}$ weak intermolecular interactions.

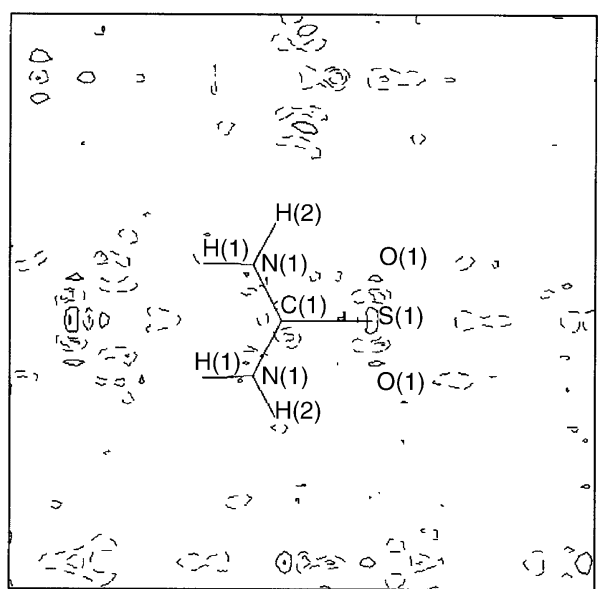

a)

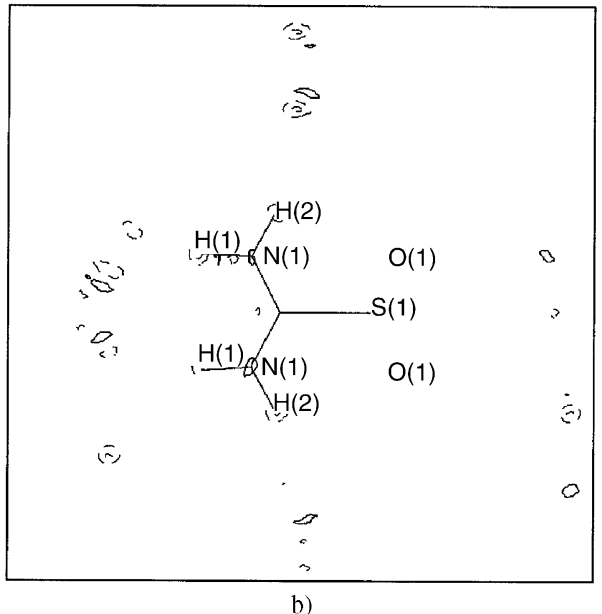

Figure 3. Residual maps after the multipole refinement based on a) experimental data and b) theoretically derived structural factors. Solid contours denote positive values, dashed contours denote negative values. The contour interval is $0.1 \mathrm{e} \AA^{-3}$.

Information. The additional parameters in the present study do improve the refinements. The refinement based on the theoretically derived structure amplitudes is particularly successful, with the lowest agreement indices shown in Table 1. The refinements on the experimental data with $\kappa^{\prime}$ constrained from, and free from, the values derived from the PDFT refinement do not appear to show any difference. The $\kappa^{\prime}$-restricted multipole model $(\mathrm{KRMM})^{[47]}$ is used for the subsequent density studies.

Intramolecular interactions: The comparison of the thiourea $S, S$-dioxide molecule with the crystal geometry (CG) and the optimized geometry (OG) in the gas phase was made, and the

Table 1. Agreement indices of various multipole refinements.

\begin{tabular}{llllllc}
\hline & $R(F)$ & $R w(F)$ & $R\left(F^{2}\right)$ & $R w\left(F^{2}\right)$ & GOF & Variable \\
\hline octapole $^{[\mathrm{a}][46]}$ & 0.0174 & 0.0217 & 0.0317 & 0.0468 & 1.47 & 97 \\
KRMM $_{\text {UMM }}^{[\mathrm{b}]}$ & 0.0169 & 0.0150 & 0.0278 & 0.0299 & 4.28 & 111 \\
PDFT/XD program & 0.0166 & 0.0149 & 0.0282 & 0.0297 & 4.25 & 115 \\
& 0.0097 & 0.0092 & 0.0119 & 0.0205 & 4.79 & 85
\end{tabular}

[a] Octapole with hexadecapole of the S atom. [b] UMM = Unrestricted multipole model. 
optimized geometry of the molecule was constrained to $C_{s}$ symmetry. Significant differences are found in these two geometries: 1) Marked lengthening of the $\mathrm{C}-\mathrm{S}$ bond length is found in the OG (1.9888 rather than $1.8592(6) \AA$ ) ; 2) a bigger dihedral angle is found between the $\mathrm{SO}_{2}$ and $\left(\mathrm{NH}_{2}\right)_{2} \mathrm{C}$ groups in the OG (78.9 compared with $\left.69.1^{\circ}\right)$; and 3) two extra intramolecular hydrogen bonds $(\mathrm{O} \cdots \mathrm{H} 2-\mathrm{N})$ are present in the OG that are absent in the CG (Figure 4). However, the
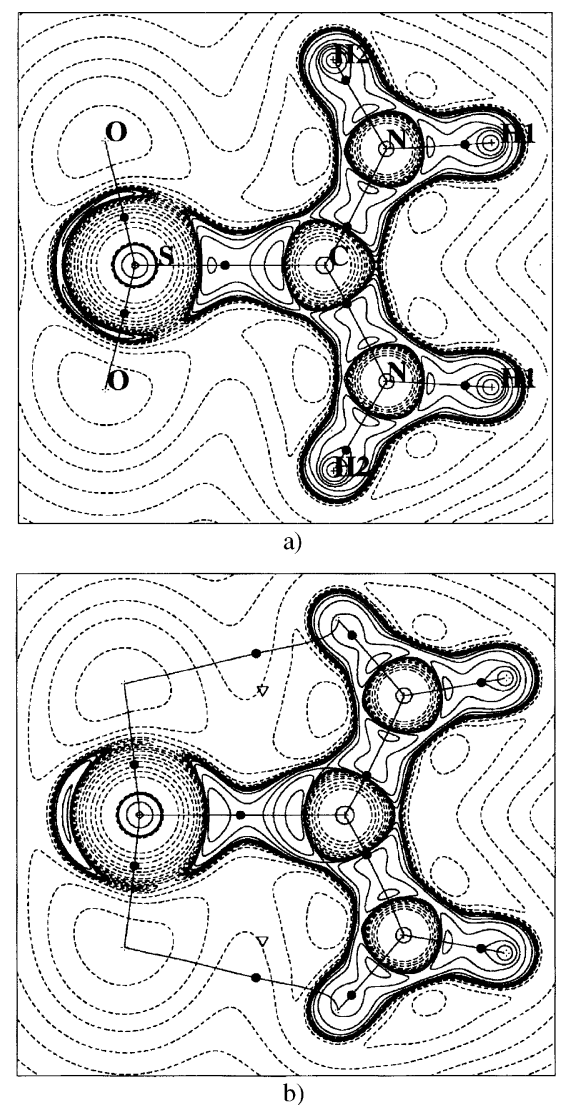

Figure 4. Laplacian charge density distributions of the molecule with a) crystal geometry, and b) optimized geometry. Dashed contours denote positive values and solid contours denote negative values. Solid circles denote the BCPs. Heavy solid lines denote the bond paths. The locations of nuclei are labeled in a). Contours are in steps of $2^{m} \times 10^{n} \mathrm{e} \AA^{-5}(m=1-3$, $n=-3-1)$.

energy difference between the two geometries is relatively small $\left(30.59 \mathrm{~kJ} \mathrm{~mol}^{-1}\right)$. Therefore the crystal geometry is used for the subsequent analyses. In the light of the topological properties analysis of the charge density distribution, the $\rho_{\mathrm{b}}$, $\nabla^{2} \rho_{\mathrm{b}}$, and $H_{\mathrm{b}}$ values (Table 2 ) of all intramolecular bonds are in good agreement between the two geometries. The only discrepancy found is the values related to the $\mathrm{S}-\mathrm{C}$ bond, due to the marked lengthening of the bond length in the OG. In addition, the charge concentration of the $\mathrm{S}$ atom is different between the $\mathrm{CG}$ and $\mathrm{OG}$ in the thiourea plane shown in Figure 4; this is apparently owing to the extra hydrogen bond in the OG. It is clearly shown that all the intramolecular bonds are covalent in character. The $\mathrm{C}-\mathrm{N}$ and $\mathrm{S}-\mathrm{O}$ bonds have relatively large $\rho_{\mathrm{b}}$ and $\left|H_{\mathrm{b}}\right|$ values, which indicates a possible double bond. The $\nabla^{2} \rho_{\mathrm{b}}$ value of the $\mathrm{S}-\mathrm{O}$ bond is positive, but the $H_{\mathrm{b}}$ value is negative and the BCP is significantly closer to
Table 2. The topological properties of the theoretically calculated charge densities at the bond critical point for the crystal geometry (CG) and the optimized geometry (OG). ${ }^{[a]}$

\begin{tabular}{llllrl}
\hline Bond & $\begin{array}{l}\text { Bond length } \\
{[\AA]}\end{array}$ & $\begin{array}{l}d 1^{[\mathrm{b}]} \\
{[\AA]}\end{array}$ & $\begin{array}{l}\rho_{\mathrm{b}} \\
{\left[\mathrm{e} \AA^{-3}\right]}\end{array}$ & $\begin{array}{l}\nabla^{2} \rho_{\mathrm{b}} \\
{\left[\mathrm{e}^{-5}\right]}\end{array}$ & $\begin{array}{l}H_{\mathrm{b}} \\
{\left[\text { Hartree } \AA^{-3}\right]}\end{array}$ \\
\hline $\mathrm{S}-\mathrm{O}$ & $1.4997(6)$ & 0.583 & 1.71 & 18.96 & -2.04 \\
& 1.509 & 0.586 & 1.68 & 17.54 & -2.00 \\
$\mathrm{~S}-\mathrm{C}$ & $1.8592(6)$ & 0.884 & 1.12 & -6.69 & -0.87 \\
& 1.988 & 0.975 & 0.88 & -2.76 & -0.50 \\
$\mathrm{C}-\mathrm{N}$ & $1.3096(7)$ & 0.444 & 2.28 & -17.90 & -4.01 \\
& 1.310 & 0.445 & 2.27 & -18.01 & -3.99 \\
$\mathrm{H} 1-\mathrm{N}$ & 1.030 & 0.259 & 2.12 & -41.18 & -3.22 \\
& 1.013 & 0.250 & 2.20 & -43.36 & -3.39 \\
$\mathrm{H} 2-\mathrm{N}$ & 1.030 & 0.238 & 2.10 & -42.24 & -3.24 \\
& 1.022 & 0.234 & 2.14 & -43.18 & -3.33 \\
$\mathrm{O} \cdots \mathrm{H} 2$ & & & & & \\
& 2.226 & 0.876 & 0.12 & 1.41 & 0.00 \\
\hline
\end{tabular}

[a] First line for the CG, second line for the OG. [b] $d 1$ is the distance from the BCP to the first atom.

the S atom; this indicates a highly polarized covalent bond, although similar findings would also occur in a very short polarized bond. ${ }^{[2,48]}$ It was reported ${ }^{[49]}$ that the $\mathrm{S}-\mathrm{O}$ bond in compounds containing a hypervalent sulfur atom in $>\mathrm{SO}$ and $>\mathrm{SO}_{2}$ fragments could involve possible participation of an ionic $\pi$ bond, however more than $90 \%$ of the charge density is located at the $\mathrm{O}$ atoms in such a $\pi$ bond. This is in agreement with the results based on a different population analysis. ${ }^{[50]}$ In one recent report, ${ }^{[51]}$ the $\mathrm{S}-\mathrm{O}$ bond was also expressed as a typical polarized $\sigma$ bond. Compared with the topological analysis of the $\mathrm{S}-\mathrm{O}$ bond in $\mathrm{Me}_{2} \mathrm{SO}_{2}$ and $\mathrm{H}_{2} \mathrm{SO}_{2}{ }^{[51]}$ this bond is longer in thiourea $S, S$-dioxide (1.500 compared with 1.456 / $1.466 \AA)$; the $\rho_{\mathrm{b}}$ and $H_{\mathrm{b}}$ values of the $\mathrm{S}-\mathrm{O}$ bond in this compound are also slightly smaller in magnitude. With a $\rho_{\mathrm{b}}$ value of $1.71 \mathrm{e}^{-3}$ (versus 1.97 in $\mathrm{Me}_{2} \mathrm{SO}_{2}$ ) and a negative $H_{\mathrm{b}}$ $\left(-2.04\right.$ Hartree $\left.\AA^{-3}\right)$, there is definitely an indication of a partial double bond, and the polarity of the charge density is toward the oxygen atom, a fact which is quite consistent with earlier findings. ${ }^{[4,51]}$ The $\mathrm{C}-\mathrm{S}$ bond is the longest single bond found in the literature. ${ }^{[46]}$ The BCP is slightly closer to the $\mathrm{S}$ atom, which indicates that the $\mathrm{S}$ atom is slightly more positive than the $\mathrm{C}$ atom; this is indeed so, as observed from the atomic charge (Table 4). The $\rho_{\mathrm{b}}$ and $\left|H_{\mathrm{b}}\right|$ values of the $\mathrm{C}-\mathrm{S}$ bond are relatively low. This indicates that the $\mathrm{C}-\mathrm{S}$ bond here is a rather weak single bond. An empirical linear correlation between the bond length and the values of $\rho_{\mathrm{b}}$ was reported recently for $\mathrm{C}-\mathrm{S}$ bonds of several sulfur-containing compounds. ${ }^{[30]}$ The $\rho_{\mathrm{b}}$ value and bond length of this molecule fit well with this linear relationship. The $\mathrm{C}-\mathrm{N}$ bond here is shorter than that of urea. ${ }^{[8]}$ The $\rho_{\mathrm{b}}$ values are comparable. The large negative $H_{\mathrm{b}}$ value of -4.01 Hartree $\AA^{-3}$ certainly indicates that the $\mathrm{C}-\mathrm{N}$ bond is more than a single bond. It was also reported that the $\pi$ character of the $\mathrm{C}-\mathrm{N}$ bond is enhanced for urea from the isolated molecule to the solid form. ${ }^{[8]}$

In order to realize the effect of intermolecular interactions exerted on the chemical bonds in the solid, the systematic topological properties analysis is applied to the theoretically calculated electron densities of a monomer, a heptamer, and a 
crystal; the results are tabulated in Table 3. The corresponding values obtained by experiment and from the multipole model imposed on theoretical structure factors are also listed in the table for comparison. The trend of strengthening the intramolecular bond in terms of $\rho_{\mathrm{b}}$ from the monomer and the heptamer to the crystal is detectable in the theoretical results.

Table 3. Intramolecular interactions: the topological properties associated with the BCPs. ${ }^{[a]}$

\begin{tabular}{|c|c|c|c|c|}
\hline $\begin{array}{l}\text { Bond/ } \\
\text { Bond length }[\AA]\end{array}$ & $\begin{array}{l}d 1 \\
{[\AA]}\end{array}$ & $\begin{array}{l}\rho_{\mathrm{b}} \\
{\left[\mathrm{e} \AA^{-3}\right]}\end{array}$ & $\begin{array}{l}\nabla^{2} \rho_{\mathrm{b}} \\
{\left[\mathrm{e} \AA^{-5}\right]}\end{array}$ & $\begin{array}{l}H_{\mathrm{b}} \\
{\left[\text { Hartree } \AA^{-3}\right]}\end{array}$ \\
\hline $\begin{array}{l}\mathrm{S}-\mathrm{O} \\
/ 1.4997(4)\end{array}$ & $\begin{array}{l}0.583 \\
0.583 \\
0.581 \\
0.609 \\
0.608\end{array}$ & $\begin{array}{l}1.709 \\
1.749 \\
1.779 \\
1.772 \\
1.852\end{array}$ & $\begin{array}{r}18.964 \\
19.469 \\
20.866 \\
6.825 \\
5.353\end{array}$ & $\begin{array}{l}-2.038 \\
-1.958 \\
-2.012 \\
-1.677 \\
-1.772\end{array}$ \\
\hline $\begin{array}{l}\mathrm{S}-\mathrm{C} \\
/ 1.8592(6)\end{array}$ & $\begin{array}{l}0.884 \\
0.922 \\
0.939 \\
0.933 \\
0.985\end{array}$ & $\begin{array}{l}1.117 \\
1.173 \\
1.186 \\
1.167 \\
1.195\end{array}$ & $\begin{array}{l}-6.686 \\
-7.790 \\
-6.984 \\
-4.967 \\
-2.977\end{array}$ & $\begin{array}{l}-0.873 \\
-0.878 \\
-0.817 \\
-0.867 \\
-0.838\end{array}$ \\
\hline $\begin{array}{l}\mathrm{C}-\mathrm{N} \\
/ 1.3096(5)\end{array}$ & $\begin{array}{l}0.444 \\
0.452 \\
0.442 \\
0.450 \\
0.479\end{array}$ & $\begin{array}{l}2.279 \\
2.322 \\
2.419 \\
2.444 \\
2.302\end{array}$ & $\begin{array}{l}-17.900 \\
-22.396 \\
-18.488 \\
-22.419 \\
-17.770\end{array}$ & $\begin{array}{l}-4.007 \\
-4.103 \\
-4.125 \\
-3.135 \\
-2.906\end{array}$ \\
\hline $\begin{array}{l}\mathrm{H} 1-\mathrm{N} \\
/ 1.030\end{array}$ & $\begin{array}{l}0.259 \\
0.237 \\
0.230 \\
0.233 \\
0.203\end{array}$ & $\begin{array}{l}2.124 \\
2.102 \\
2.170 \\
1.916 \\
1.776\end{array}$ & $\begin{array}{l}-41.180 \\
-41.805 \\
-41.395 \\
-30.605 \\
-29.992\end{array}$ & $\begin{array}{l}-3.224 \\
-3.246 \\
-3.217 \\
-2.482 \\
-2.382\end{array}$ \\
\hline $\begin{array}{l}\mathrm{H} 2-\mathrm{N} \\
/ 1.030\end{array}$ & $\begin{array}{l}0.238 \\
0.224 \\
0.230 \\
0.241 \\
0.179\end{array}$ & $\begin{array}{l}2.102 \\
2.077 \\
2.170 \\
1.946 \\
1.532\end{array}$ & $\begin{array}{l}-42.242 \\
-41.942 \\
-41.395 \\
-30.513 \\
-25.074\end{array}$ & $\begin{array}{l}-3.238 \\
-3.227 \\
-3.227 \\
-2.503 \\
-2.165\end{array}$ \\
\hline $\begin{array}{l}\mathrm{S}-\mathrm{O}^{[51]} \\
/ 1.456\end{array}$ & & 1.97 & 22.94 & -2.38 \\
\hline $\begin{array}{l}\mathrm{S}-\mathrm{O}^{[51]} \\
/ 1.466\end{array}$ & & 1.94 & 20.55 & -2.36 \\
\hline $\begin{array}{l}\mathrm{S}-\mathrm{O}^{[51]} \\
/ 1.514\end{array}$ & & 0.878 & -1.357 & -0.502 \\
\hline $\begin{array}{l}\mathrm{S}-\mathrm{C}^{[30]} \\
/ 1.712\end{array}$ & $\begin{array}{l}0.79 \\
0.71\end{array}$ & $\begin{array}{l}1.36 \\
1.42\end{array}$ & $\begin{array}{l}-3.75 \\
-8.97\end{array}$ & $\begin{array}{l}-1.03 \\
-1.60\end{array}$ \\
\hline $\begin{array}{l}\mathrm{S}-[30] \\
/ 1.824\end{array}$ & $\begin{array}{l}0.96 \\
0.96\end{array}$ & $\begin{array}{l}1.21 \\
1.22\end{array}$ & $\begin{array}{l}-3.53 \\
-6.78\end{array}$ & $\begin{array}{l}-0.90 \\
-0.83\end{array}$ \\
\hline $\begin{array}{l}\mathrm{S}-\mathrm{C}^{[30]} \\
/ 1.721\end{array}$ & $\begin{array}{l}0.83 \\
0.78\end{array}$ & $\begin{array}{l}1.35 \\
1.40\end{array}$ & $\begin{array}{l}-6.91 \\
-9.78\end{array}$ & $\begin{array}{l}-1.13 \\
-1.37\end{array}$ \\
\hline $\begin{array}{l}\mathrm{S}-\mathrm{C}^{[30]} \\
/ 1.657\end{array}$ & $\begin{array}{l}0.78 \\
0.64\end{array}$ & $\begin{array}{l}1.50 \\
1.45\end{array}$ & $\begin{array}{r}-4.87 \\
0.18\end{array}$ & $\begin{array}{l}-1.46 \\
-1.71\end{array}$ \\
\hline $\begin{array}{l}\mathrm{C}-\mathrm{N}^{[30]} \\
/ 1.326\end{array}$ & $\begin{array}{l}0.71 \\
0.45\end{array}$ & $\begin{array}{l}2.45 \\
2.30\end{array}$ & $\begin{array}{l}-11.15 \\
-18.05\end{array}$ & $\begin{array}{l}-2.43 \\
-3.83\end{array}$ \\
\hline $\begin{array}{l}\mathrm{C}-\mathrm{N}^{[30]} \\
/ 1.318\end{array}$ & $\begin{array}{l}0.69 \\
0.45\end{array}$ & $\begin{array}{l}2.53 \\
2.32\end{array}$ & $\begin{array}{r}-6.28 \\
-18.43\end{array}$ & $\begin{array}{l}-2.95 \\
-3.83\end{array}$ \\
\hline $\begin{array}{l}\mathrm{C}-\mathrm{N}^{[30]} \\
/ 1.338\end{array}$ & $\begin{array}{l}0.60 \\
0.46\end{array}$ & $\begin{array}{l}2.51 \\
2.27\end{array}$ & $\begin{array}{l}-24.80 \\
-21.35\end{array}$ & $\begin{array}{l}-2.82 \\
-3.73\end{array}$ \\
\hline $\begin{array}{l}\mathrm{C}-\mathrm{N}^{[8]} \\
/ 1.345\end{array}$ & $\begin{array}{l}0.442 \\
0.451\end{array}$ & $\begin{array}{l}2.30 \\
2.36\end{array}$ & $\begin{array}{l}-22.65 \\
-27.71\end{array}$ & - \\
\hline $\begin{array}{l}\mathrm{C}-\mathrm{N}^{[75]} \\
/ 1.322\end{array}$ & $\begin{array}{l}0.52 \\
0.52\end{array}$ & $\begin{array}{l}2.31 \\
2.39\end{array}$ & $\begin{array}{l}-20.65 \\
-21.39\end{array}$ & - \\
\hline
\end{tabular}

[a] For thiourea $S, S$-dioxide: first line from DFT calculations of monomer, second line from DFT calculations of heptamer, third line from DFT calculations of crystal, fourth line from PDFT/XD program, fifth line from KRMM. For other compounds (with references): first line from calculations, second line from experiment.
Some discrepancies of the topological properties are found between the experimental and theoretical values, particularly on the sign of the $\nabla^{2} \rho_{\mathrm{b}}$ value of $\mathrm{S}-\mathrm{O}$ bonds. It is noticeable that the $\mathrm{BCP}$ of the $\mathrm{S}-\mathrm{O}$ bond observed in the experiment is not as close to the $\mathrm{S}$ atom as in the theoretical calculations, therefore the $\lambda_{3}$ value is reasonable to make the $\nabla^{2} \rho_{\mathrm{b}}$ negative as expected. ${ }^{[48]}$ It was pointed out ${ }^{[52]}$ that topological discrepancies between experimental and theoretical crystal charge densities are mainly attributed to the nature of the radial function in the experimental multipole model, which would result in the difference of the $\lambda_{3}$ value. It is worth mentioning that the intramolecular bonds, except the $\mathrm{N}-\mathrm{H}$ bond, are all enhanced by the intermolecular interactions according to the topological analyses. The $\mathrm{N}-\mathrm{H}$ bonds are weakened in the solid, which is expected when the corresponding intermolecular hydrogen bond is strengthened. In general, the agreement in $\rho_{\mathrm{b}}$ between the experiment and theory improves when intermolecular interactions are taken into account from a monomer to a heptamer and then to a crystal. However, the $H_{\mathrm{b}}$ values do not follow the same trend. This may result from the approximate expression ${ }^{[19,53-55]}$ in the experimental values, which does not strictly fit for a covalent bond.

Atomic domains and atomic net charges: According to AIM theory, ${ }^{[2]}$ a set of zero-flux surfaces partitions the molecule into unique atom domains $(\Omega)$. These zero-flux surfaces projected onto a molecular plane, which contained the $\mathrm{S}, \mathrm{C}$, and $\mathrm{N}$ atoms of a moiety, together with the total electron density distribution, bond paths, and BCPs, are illustrated in Figure 5 from a DFT calculation of a heptamer model and from experimental results. The shape and the size of these domains are nearly identical between the theory and experiment.

The AIM net atomic charge $\left(q_{\Omega}\right)$ can be obtained by numerical integration of the electron density distribution within the atomic domain $(\Omega)$ and subtraction from the atomic number $\left(Z_{n}\right): q_{\Omega}=Z_{n}-\int_{\Omega} \rho(\boldsymbol{r}) \mathrm{d} \tau$. The net atomic charges and the fragment charges are tabulated in Table 4. The $\mathrm{H}, \mathrm{C}$, and $\mathrm{S}$ atoms are positively charged and the $\mathrm{O}$ and $\mathrm{N}$ atoms are negatively charged. The agreement between experiment and theory is reasonable. This charge distribution gives a positive $\mathrm{C}\left(\mathrm{NH}_{2}\right)_{2}$ moiety and a negative $\mathrm{SO}_{2}$ fragment, which fits the zwitterionic description; however the negative charge is mainly on the $\mathrm{O}$ atoms of the $\mathrm{SO}_{2}$ fragment. The dipole moment of the molecule seems to be enhanced from the monomer to the crystal (12.6 versus 14.6 Debye), which was also found in the case of urea $(2.02 \text { versus } 2.77 \text { Debye })^{[8]}$ and nitro aniline compounds (13.3 versus 16.1 Debye). ${ }^{[56,57]}$ The dipole moment derived from the Mulliken charges or the monopole values obtained from the multipole refinement gives roughly the same value. This confirms the earlier finding. ${ }^{[47]}$

\section{Intermolecular interactions}

Intermolecular hydrogen bonding: The existence of two types of hydrogen bonds is confirmed by the topological properties analysis of electron density (Table 5). According to the topological properties associated with the BCP of the 


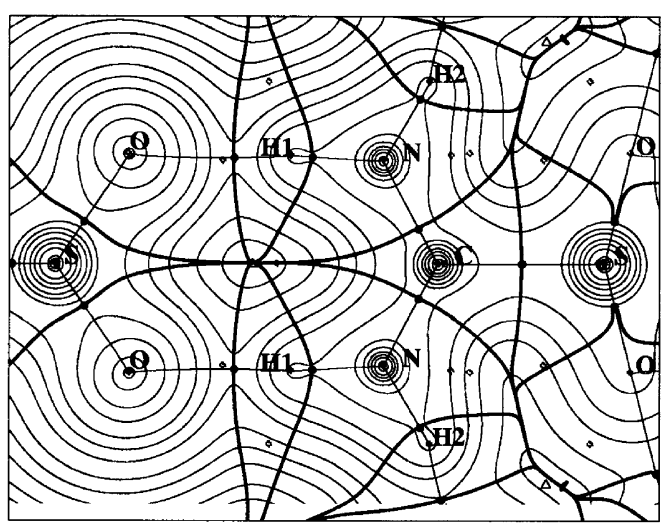

a)

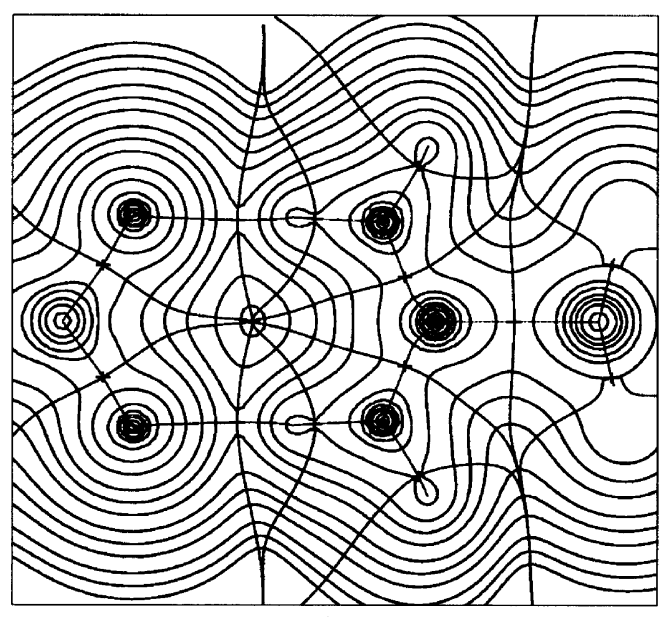

b)

Figure 5. Total electron density, $\rho(\boldsymbol{r})$, bond paths, and atom domains partitioning by zero-flux surfaces in the molecular plane derived from a) the DFT calculation of a heptamer and b) experimental diffraction data. The nuclei at the plane are labeled in (a). The charge density contours are in steps of $2^{m} \times 10^{n} \mathrm{e} \AA^{-3}(m=1-3, n=-3-3)$.

$\mathrm{H} 1 \cdots \mathrm{O}$ and $\mathrm{H} 2 \cdots \mathrm{O}$ hydrogen bonds, these are relatively strong hydrogen bonds with a $\rho_{\mathrm{b}}$ value of $\approx 0.2 \mathrm{e} \AA^{-3}$, which is in accordance with values obtained elsewhere, ${ }^{[19,21,55]}$ for

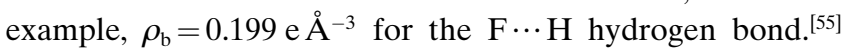
There is no obvious difference in the $\rho_{\mathrm{b}}$ or $H_{\mathrm{b}}$ values from a dimer, a heptamer, and a crystal; nevertheless the experimental values are significantly lower. However the kinetic energy density, $G_{\mathrm{b}}$ (Table 5) fits well with the exponential expression given in the literature. ${ }^{[19]}$ It also fits in the linear relationship ${ }^{[33]}$ between $G_{\mathrm{b}}$ and $\lambda_{3}$. The $\rho_{\mathrm{b}}$ value of the $\mathrm{O} \cdots \mathrm{H} 1$ bond is slightly larger than the $\mathrm{O} \cdots \mathrm{H} 2$ interaction. The BSSE (basis set superposition error) corrected binding interaction energies are calculated based on the specifically chosen dimers shown in Figures 6 and 7. This correction results in energies of -40.83 and $-54.53 \mathrm{~kJ} \mathrm{~mol}^{-1}$ for $\mathrm{N}-\mathrm{H} 1 \cdots \mathrm{O}$ and $\mathrm{N}-\mathrm{H} 2 \cdots \mathrm{O}$, respectively. In general the nonbonded charge concentrations are the preferred sites of protonation. There are two Laplacian charge concentrations (vertex critical point in the atomic graph) in the valence-shell charge concentration (VSCC) of the $\mathrm{O}$ atom (see Supporting Information) and a Laplacian local minimum (face critical point) of hydrogen toward this charge concentration of the $\mathrm{O}$ atom. In principle, the locations of the $\mathrm{N}-\mathrm{H}$ bond with its Laplacian local minimum and the charge concentration of $\mathrm{O}$ should be in alignment as far as possible. This is true in cases of both $\mathrm{N}-\mathrm{H} 2 \cdots \mathrm{O}$ and $\mathrm{N}-\mathrm{H} 1 \cdots \mathrm{O}$ hydrogen bonds. A similar feature was reported in crystalline urea ${ }^{[8]}$ Furthermore the BSSEcorrected binding energies of $\mathrm{N}-\mathrm{H} 1 \cdots \mathrm{O}$ and $\mathrm{N}-\mathrm{H} 2 \cdots \mathrm{O}$ were calculated for a trimer including both $\mathrm{N}-\mathrm{H} 1 \cdots \mathrm{O}$ and $\mathrm{N}-\mathrm{H} 2 \cdots \mathrm{O}$ type interactions. The values were -45.66 and $-54.15 \mathrm{~kJ} \mathrm{~mol}^{-1}$, respectively. The binding energies increase a bit for the $\mathrm{N}-\mathrm{H} 1 \cdots \mathrm{O}$ bond from a dimer to a trimer.

Weak intermolecular binding interactions $C \cdots S^{\prime}$ and $O \cdots N^{\prime}$ : In addition to the intermolecular hydrogen bonds, the thiourea $S, S$-dioxide molecules in the crystal are linked to one another through weak $\mathrm{C} \cdots \mathrm{S}^{\prime}$ and $\mathrm{O} \cdots \mathrm{N}^{\prime}$ binding interactions between neighboring moieties (Figure $2 \mathrm{c}$ ). These binding interactions are again confirmed by the location of the BCPs and the trace of the associated bond path to the relevant nuclei, as displayed in Figure 8. The related topological properties are listed in Table 5. It is obvious that the $\rho_{\mathrm{b}}$ values (approximately $0.02-0.06 \mathrm{e}^{-3}$ ) are much less than those of hydrogen bonds $\left(\approx 0.2 \mathrm{e} \AA^{-3}\right)$. The bond paths of $\mathrm{C} \cdots \mathrm{S}^{\prime}$ and $\mathrm{O} \cdots \mathrm{N}^{\prime}$ are slightly longer than the respective geometrical distances (bond lengths), so they are slightly bent as shown in Figure 8 . The nature of these weak intermolecular binding interactions can be understood correctly by the VSCC Laplacian critical points. The 3D isovalue surfaces of Laplacian distributions derived by experiment and theory are depicted in Figure 9, where a nonbonded charge concentration is located at the VSCC of the S atom and two charge depletions are located above and below the $\mathrm{C}$ atom. While in the crystal, the nonbonded charge concentration of the $\mathrm{S}$ atom is directly inserted toward the charge depletion of the $\mathrm{C}$ atom from the molecule below to form the $\mathrm{C} \cdots \mathrm{S}^{\prime}$ binding interactions (Figure 9a, b). In other words, the nonbonded Laplacian charge concentration of the $\mathrm{S}$ atom serves as a Lewis base or an electrophile and the Laplacian charge

Table 4. The atomic AIM charges $\left(q_{\Omega}\right)$ and the molecular dipole moments (Debye).

\begin{tabular}{|c|c|c|c|c|c|}
\hline Atom & Monomer & Heptamer & PDFT & PDFT/XD program & Experiment/KRMM \\
\hline $\mathrm{S}$ & 2.164 & 2.141 & 2.145 & 1.955 & 1.759 \\
\hline $\mathrm{O}$ & -1.313 & -1.347 & -1.362 & -1.339 & -1.255 \\
\hline $\mathrm{N}$ & -1.287 & -1.386 & -1.407 & -1.246 & -1.452 \\
\hline $\mathrm{C}$ & 1.214 & 1.221 & 1.277 & 0.790 & 0.893 \\
\hline $\mathrm{H} 1$ & 0.410 & 0.502 & 0.522 & 0.611 & 0.671 \\
\hline $\mathrm{H} 2$ & 0.500 & 0.550 & 0.538 & 0.602 & 0.707 \\
\hline $\mathrm{SO}_{2}$ & -0.46 & -0.55 & -0.58 & -0.72 & -0.75 \\
\hline dipole moment & 12.6 & 14.2 & 14.6 & 15.5 & 16.3 \\
\hline
\end{tabular}


Table 5. Intermolecular interactions: the topological properties associated with the BCPs. ${ }^{[a]}$

\begin{tabular}{|c|c|c|c|c|c|c|}
\hline $\begin{array}{l}\text { Bond/bond length }[\AA] / \\
\text { bond path }[\AA]\end{array}$ & $\begin{array}{l}d 1 \\
{[\AA]}\end{array}$ & $\begin{array}{l}\rho_{\mathrm{b}} \\
{\left[\mathrm{e} \AA^{-3}\right]}\end{array}$ & $\begin{array}{l}\nabla^{2} \rho_{\mathrm{b}} \\
{\left[\mathrm{e} \AA^{-5}\right]}\end{array}$ & $\begin{array}{l}G_{\mathrm{b}} \\
{\left[\text { Hartree } \AA^{-3}\right]}\end{array}$ & $\begin{array}{l}H_{\mathrm{b}} \\
{\left[\text { Hartree } \AA^{-3}\right]}\end{array}$ & $\begin{array}{l}\Delta E^{[\mathrm{b}]} \\
{\left[\mathrm{kJ} \mathrm{mol}^{-1}\right]}\end{array}$ \\
\hline $\begin{array}{l}\mathrm{O} \cdots \mathrm{H} 1 \\
/ 1.810(2) \\
/ 1.811\end{array}$ & $\begin{array}{l}1.176 \\
1.179 \\
1.179 \\
1.192 \\
1.202\end{array}$ & $\begin{array}{l}0.222 \\
0.225 \\
0.235 \\
0.216 \\
0.178\end{array}$ & $\begin{array}{l}2.486 \\
2.479 \\
2.376 \\
2.232 \\
2.883\end{array}$ & $\begin{array}{l}0.176 \\
0.176 \\
0.171 \\
0.167 \\
0.180\end{array}$ & $\begin{array}{r}-0.002 \\
-0.003 \\
-0.005 \\
0.010 \\
0.022\end{array}$ & -40.83 \\
\hline $\begin{array}{l}\mathrm{O} \cdots \mathrm{H} 2 \\
/ 1.843(2) \\
/ 1.849\end{array}$ & $\begin{array}{l}1.199 \\
1.197 \\
1.189 \\
1.221 \\
1.237\end{array}$ & $\begin{array}{l}0.199 \\
0.196 \\
0.204 \\
0.166 \\
0.146\end{array}$ & $\begin{array}{l}2.171 \\
2.210 \\
2.267 \\
2.649 \\
2.323\end{array}$ & $\begin{array}{l}0.152 \\
0.155 \\
0.157 \\
0.164 \\
0.141\end{array}$ & $\begin{array}{l}0.000 \\
0.001 \\
0.002 \\
0.022 \\
0.022\end{array}$ & -54.53 \\
\hline $\begin{array}{l}S \cdots C^{\prime} \\
/ 3.3128(6) \\
/ 3.323\end{array}$ & $\begin{array}{l}1.820 \\
1.813 \\
1.805 \\
1.776 \\
1.769\end{array}$ & $\begin{array}{l}0.054 \\
0.055 \\
0.058 \\
0.064 \\
0.062\end{array}$ & $\begin{array}{l}0.649 \\
0.666 \\
0.659 \\
0.718 \\
0.766\end{array}$ & $\begin{array}{l}0.031 \\
0.036 \\
0.036 \\
0.042 \\
0.044\end{array}$ & $\begin{array}{l}0.010 \\
0.010 \\
0.010 \\
0.009 \\
0.010\end{array}$ & -9.48 \\
\hline $\begin{array}{l}\mathrm{O} \cdots \mathrm{N}^{\prime} \\
/ 3.619(2) \\
/ 3.630\end{array}$ & $\begin{array}{l}1.794 \\
1.787 \\
1.791 \\
1.851 \\
1.836\end{array}$ & $\begin{array}{l}0.018 \\
0.019 \\
0.019 \\
0.017 \\
0.019\end{array}$ & $\begin{array}{l}0.270 \\
0.278 \\
0.279 \\
0.247 \\
0.261\end{array}$ & $\begin{array}{l}0.015 \\
0.016 \\
0.016 \\
0.012 \\
0.013\end{array}$ & $\begin{array}{l}0.004 \\
0.004 \\
0.004 \\
0.005 \\
0.005\end{array}$ & -5.80 \\
\hline $\begin{array}{l}\mathrm{O} \cdots \mathrm{H}^{[21]} \\
/ 1.72\end{array}$ & & $\begin{array}{l}0.273 \\
0.295\end{array}$ & $\begin{array}{l}3.40 \\
3.10\end{array}$ & $\begin{array}{l}0.216 \\
0.242\end{array}$ & $\begin{array}{l}-0.013 \\
-0.020\end{array}$ & \\
\hline $\begin{array}{l}\mathrm{O} \cdots \mathrm{H}^{[21]} \\
/ 1.81\end{array}$ & & $\begin{array}{l}0.230 \\
0.248\end{array}$ & $\begin{array}{l}2.88 \\
2.66\end{array}$ & $\begin{array}{l}0.202 \\
0.202\end{array}$ & $\begin{array}{l}0.000 \\
0.000\end{array}$ & \\
\hline $\begin{array}{l}\mathrm{O} \cdots \mathrm{H}^{[21]} \\
/ 1.93\end{array}$ & & $\begin{array}{l}0.174 \\
0.188\end{array}$ & $\begin{array}{l}2.49 \\
2.30\end{array}$ & $\begin{array}{l}0.155 \\
0.149\end{array}$ & $\begin{array}{l}0.013 \\
0.007\end{array}$ & \\
\hline
\end{tabular}

[a] First line from DFT calculations of chosen dimers, second line from DFT calculation of heptamer, third line from PDFT calculations of crystal, fourth line from PDFT/XD program, fifth line from KRMM. The intermolecular binding interaction energies are calculated based on the corresponding dimer models in the BSSE correction.

depletion of the $\mathrm{C}$ atom is the Lewis acid or a nucleophile. Similarly the $\mathrm{N}$ atom possesses two nonbonded charge concentrations, one on each side of the plane. One of these charge concentrations of the $\mathrm{N}$ atom can align itself toward the Laplacian charge depletion of the $\mathrm{O}$ atom of a neighbouring molecule to form the $\mathrm{O} \cdots \mathrm{N}^{\prime}$ binding interaction. These weak $\mathrm{C} \cdots \mathrm{S}$ and $\mathrm{N} \cdots \mathrm{O}$ interactions together with hydrogen bonds demonstrate the 3D directional "key-lock" architecture in the crystal. Based on the chosen dimer model, the BSSE-corrected binding interaction energies, $\Delta E$, are -9.48 and $-5.80 \mathrm{~kJ} \mathrm{~mol}^{-1}$ for $\mathrm{C} \cdots \mathrm{S}^{\prime}$ and $\mathrm{O} \cdots \mathrm{N}^{\prime}$, respectively.

\section{Conclusion}

An exact comparison has been accomplished between the experiment and theory of electron density based on the multipole model. The covalent bonding characters of the $\mathrm{C}-\mathrm{S}$, $\mathrm{S}-\mathrm{O}$, and $\mathrm{C}-\mathrm{N}$ bonds in thiourea $S, S$-dioxide have been illustrated by topological analysis. The partial double bond character of the $\mathrm{S}-\mathrm{O}$ and $\mathrm{C}-\mathrm{N}$ bonds is recognized, with ionic $\pi$ character of the $\mathrm{S}-\mathrm{O}$ bond. A highly polar single $\mathrm{C}-\mathrm{S}$ bond between two oppositely charged fragments has been established. The large dipole moment results from a positive $\mathrm{C}\left(\mathrm{NH}_{2}\right)_{2}$ moiety and a negative $\mathrm{SO}_{2}$ fragment, a firm illustration of the zwitterionic character. Two categories of intermolecular interactions are identified: the relatively strong hydrogen bonds, with $\rho_{\mathrm{b}} \approx 0.2 \mathrm{e} \AA^{-3}$ and binding energies $(\Delta E)$ of $\approx 50 \mathrm{~kJ} \mathrm{~mol}^{-1}$, and the relatively weak $\mathrm{C} \cdots \mathrm{S}^{\prime}$ and $\mathrm{O} \cdots \mathrm{N}^{\prime}$ interactions, with $\rho_{\mathrm{b}} \approx 0.02-0.05 \mathrm{e} \AA^{-3}$ and $\Delta E \approx 6-9 \mathrm{~kJ} \mathrm{~mol}^{-1}$. The natures of these intermolecular interactions have been demonstrated as $3 \mathrm{D}$ directional interactions. The effect of such intermolecular interactions on the chemical bond is detected through the systematic studies. The chemical reactivity of this molecule can be understood according to the fragment charges of the $\mathrm{SO}_{2}$ and $\mathrm{C}\left(\mathrm{NH}_{2}\right)_{2}$ groups as well as the knowledge of VSCC distribution.

\section{Computational Methods}

Multipole refinement: Thiourea $S, S$-dioxide was prepared by oxidation of thiourea with hydrogen peroxide at $0{ }^{\circ} \mathrm{C}$ and crystallized in an aqueous solution. ${ }^{[45]}$ The intensity data were collected on a CAD4 diffractometer at 110 K. Details were described in our previous work. ${ }^{[46]}$ A multipole model refinement was reinvestigated by using the XD program. ${ }^{[58]}$ The multipolar model is expressed as a series expansion of spherical harmonic terms $\left(y_{\mathrm{lmp}}\right)$ multiplied by a Slater-type radial function $R_{l}(r) \cdot{ }^{[17,59]}$ Spherical harmonic expansion terms up to hexadecapoles were included for $\mathrm{S}$ atoms, up to octapoles for $\mathrm{O}, \mathrm{N}$, and $\mathrm{C}$ atoms, and up to quadruples for $\mathrm{H}$ atoms. The core and valence electron scattering factors for each atom are taken from International Tables for X-ray Crystallography (1974, Vol. IV). The core electron configurations are assumed to have $\mathrm{Ne}$ core for $\mathrm{S}$ and He core for $\mathrm{O}, \mathrm{N}$, and $\mathrm{C}$ atoms. During the refinement, $\mathrm{H}$ atoms are moving along $\mathrm{N}-\mathrm{H}$ vectors to make an $\mathrm{N}-\mathrm{H}$ distance of $1.03 \AA$. ${ }^{600]}$ The $n_{l}$ values $(l=1-4)$ of S are $4,4,4,4$, those of $\mathrm{N}, \mathrm{O}$, and $\mathrm{C}$ are $2,2,3$, and those of $\mathrm{H}$ are 1,2 . The $\kappa^{\prime}$ restricted multipole model $(\mathrm{KRMM})^{[47]}$ was carried out at the final stage. The radial $\kappa^{\prime}$ coefficients were fixed at values derived from multipole refinement of theoretical structure factors obtained from PDFT calculations $\left(\kappa^{\prime}\right.$ coefficient for $\mathrm{S}: 0.890 ; \mathrm{O}: 2.315 ; \mathrm{N}: 0.939 ; \mathrm{C}: 0.725 ;$ and $\left.\mathrm{H}: 1.2\right)$. 


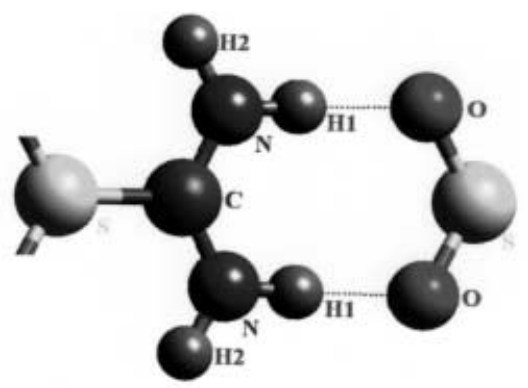

a)

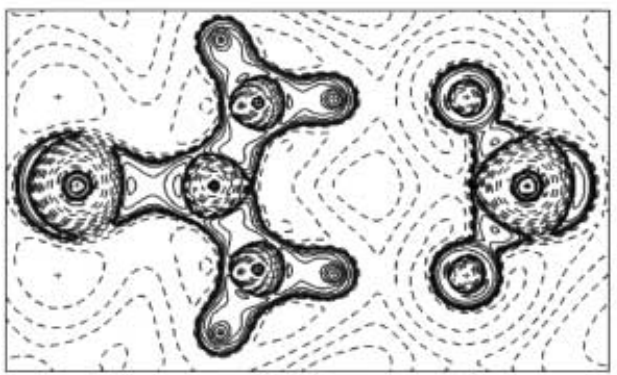

c)

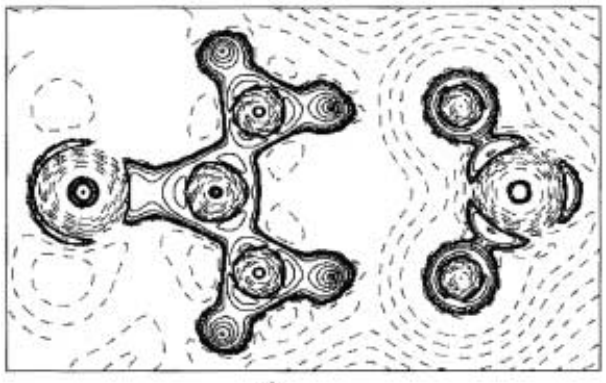

e)

Figure 6. a) Model of the chosen dimer with $\mathrm{O} \cdots \mathrm{H} 1-\mathrm{N}$ hydrogen bonds. Laplacian charge density distributions in the plane containing $\mathrm{O} \cdots \mathrm{H} 1-\mathrm{N}$ hydrogen bonds are shown as calculated from b) the DFT calculation of the chosen dimer, c) the PDFT calculation, d) the multipole model of theoretically derived structure factors and e) the multipole model of experimental data. Contours are stepped as in Figure 4.

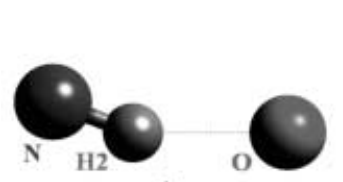

a)

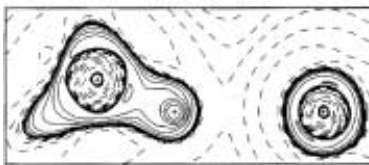

c)

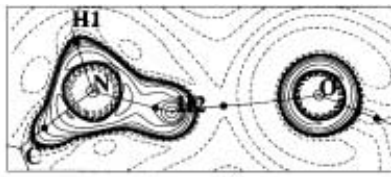

b)

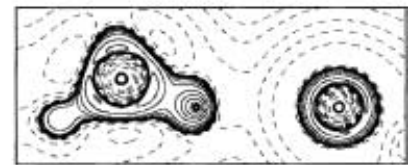

d)

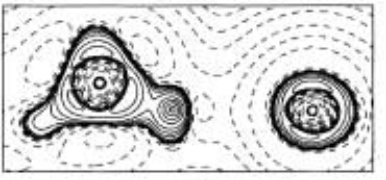

e)

Figure 7. a) Model of the $\mathrm{O} \cdots \mathrm{H} 2-\mathrm{N}$ hydrogen bond. Laplacian charge density distributions of the $\mathrm{O} \cdots \mathrm{H} 2-\mathrm{N}$ hydrogen bond are shown in b)-e) as defined as in Figure 6. Contours are stepped as in Figure 4.
The $\zeta$ values of $\mathrm{H}, \mathrm{N}, \mathrm{O}$, and $\mathrm{S}$ are 3.1762 , 3.8407, 4.4724 and 3.9496, respectively. The experimental Laplacian distributions are depicted with the XD program, ${ }^{[58]}$ and the contour maps of the charge density distributions, zero-flux surfaces, and bond paths are drawn with the PROP program. ${ }^{[61]}$

The total energy density at the bond critical point $H_{\mathrm{b}}$ values evaluated from the experimental electron density by the multipole model was derived according to the approximate expression, ${ }^{[54]}$ where the kinetic energy density, $G_{\mathrm{b}}$, is directly related to the electron density, introduced by the semiclassical Thomas - Fermi equation, where $\Delta \rho(r)=\rho(r)-\rho_{\mathrm{ci}}(r)$; in practice, $\rho_{\mathrm{ci}}(r)$ is the deformation density, that is, $\rho_{\mathrm{ci}}\left(r_{\mathrm{c}}\right)=\rho_{\mathrm{mul}}\left(r_{\mathrm{c}}\right)-\rho_{\text {iam }}\left(r_{\mathrm{c}}\right)$. The $H_{\mathrm{b}}$ value is the sum of $G_{\mathrm{b}}$ and $V_{\mathrm{b}}$, which can be estimated roughly by this generalized approach.

Theoretical calculations: All DFT ${ }^{[62]}$ calculations, including those for the single molecule and oligomers of thiourea $S, S$ dioxide, were carried out with the GAUSSIAN 98 program. ${ }^{[63]}$ The correlation correction by Lee, Yang, and Parr (LYP) $)^{[64]}$

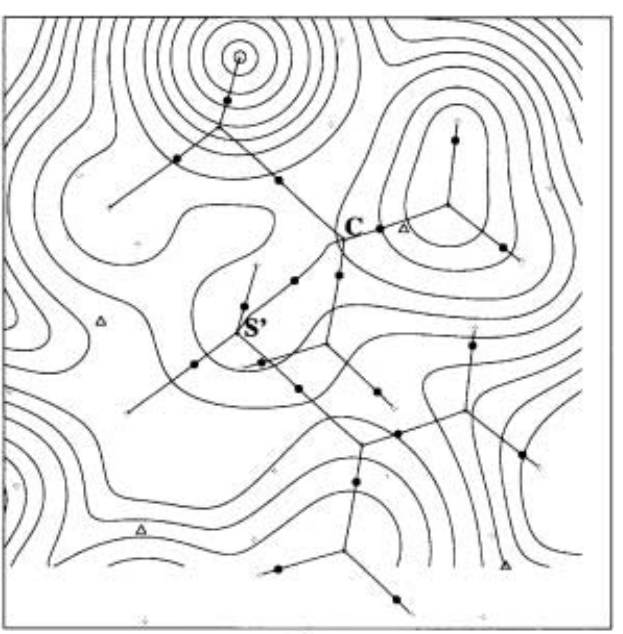

a)

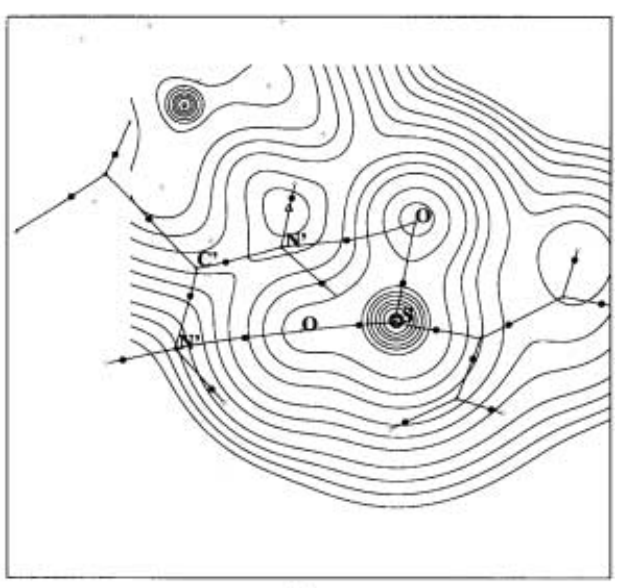

b)

Figure 8. Weak intermolecular interactions indicated by bond paths (black lines), critical points (black dots), and charge density distribution (contours) in a heptamer model: a) $\mathrm{C} \cdots \mathrm{S}^{\prime}$ interaction, b) $\mathrm{O} \cdots \mathrm{N}^{\prime}$ interaction. Contours in $\rho(\boldsymbol{r})$ are stepped as in Figure 5. 


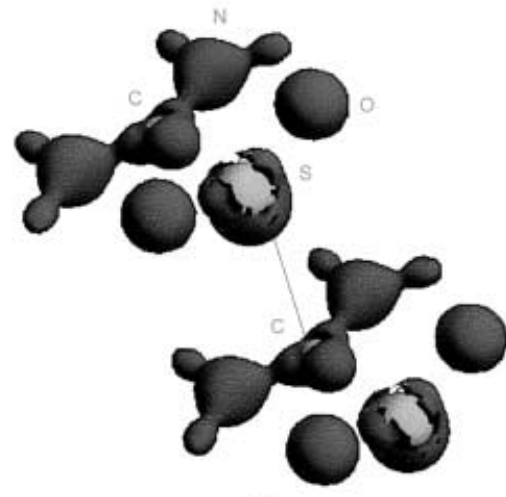

a)

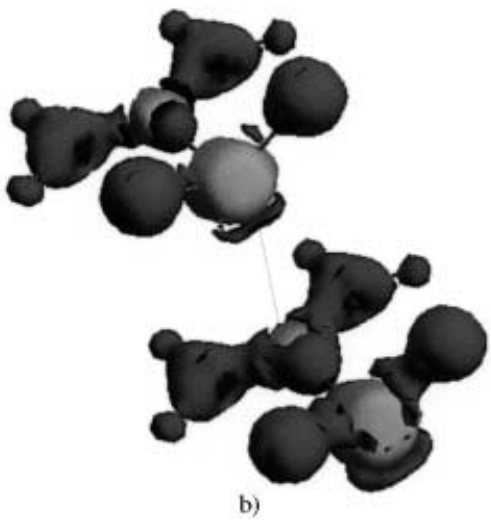

Figure 9. The isovalue surfaces $\left(\nabla^{2} \rho(\boldsymbol{r})=-11.0 \mathrm{e} \AA^{-5}\right)$ of Laplacian distributions concerning the $\mathrm{C} \cdots \mathrm{S}^{\prime}$ interaction between two moieties from a) theory based on a heptamer model and b) experiment.

together with Becke's nonlocal, gradient approach to the exchange functional in its three-parameter hybrid density form (B3LYP) ${ }^{[65]}$ was used. The standard split-valence 6-31G(d,p) basis set ${ }^{[62,66]}$ was employed for all the calculations. Fully PDFT calculation of the crystal was incorporated in the CRYSTAL algorithm by Saunders et al. ${ }^{[67]}$ by using the CRYSTAL 98 program. ${ }^{[67]}$ According to the Bloch function for an insulator, the K-point sampling of 6,6 , and 6 was chosen isotropically along the reciprocal axis a*, $\mathrm{b}^{*}$, and $\mathrm{c}^{*}$ respectively. The structural amplitudes $\left(F_{\text {the }}\right)$ were thus derived from this calculation. The multipole refinement ${ }^{[59]}$ was then applied to these theoretically calculated structural amplitudes, and the $\kappa^{\prime}$ thus obtained was adapted in the experimental multipole model.

Topological properties analysis: The total electron density obtained from the experiment was calculated according to the multipole refinement model. ${ }^{[59]}$ The total electron density for the theoretical model was calculated on the basis of the aforementioned DFT and PDFT calculations. The topological properties, maps of the charge density distributions, and Laplacian distributions were performed with the programs AIMPAC ${ }^{[68]}$ and AIM98PC ${ }^{[69]}$ for the single molecule and oligomers, with the program $\mathrm{TOPOND}^{[70]}$ used for the crystal.

The magnitude of the electron density at the $\mathrm{BCP}, \rho_{\mathrm{b}}$, correlates with the bond distance and the bond order and, therefore, with the bond strength. ${ }^{[71,72]}$ The sign of the Laplacian distribution of $\rho$ at the BCP, $\nabla^{2} \rho_{\mathrm{b}}$, could be used to distinguish bonding features between a shared interaction (covalent bond) and a closed-shell interaction (ionic bond). It was suggested ${ }^{[27,73]}$ that the negative total energy density value, $H_{\mathrm{b}}$, at the $\mathrm{BCP}$ can be interpreted as the sufficient condition of a covalent bond and could be used as a qualitative measure for covalence. Correlation between the bonding and strain energies of hydrocarbon molecules was reported with $\rho_{\mathrm{b}}$ and $H_{\mathrm{b}}$ values. ${ }^{[74]}$ The network of bond paths defines the shape of the molecule. A gradient path for which the electron density decreases most rapidly is developed in all directions normal to the bond. The set of such gradient paths starting at each BCP defines a zero-flux surface separating two bonded atoms. The network of these surfaces (one per bond) will partition the molecule into unique atomic domains (basins) for which the hypervirial theorem is satisfied. Numerical integration of the electron density within such a region yields the net charge of the given atom ${ }^{[75]}$ called the AIM charge. The Laplacian distribution, $\nabla^{2} \rho(\boldsymbol{r})$, is also a very useful tool for understanding the chemical reactivity and revealing a simple 3D directional interaction in the molecular crystal. Similarly to the aforementioned $\rho(\boldsymbol{r})$ distribution, the topological properties of $\nabla^{2} \rho(\boldsymbol{r})$ can be summarized by its critical points. The atomic graph thus defined denotes the connectivity of the local valence shell charge concentration (VSCC). Such a polyhedron obeys Eular's formula: $V-E+F=2$, where V, E, F stand for the number of vertices, edges, and faces, respectively. A correlation between these critical points of $\nabla^{2} \rho(\boldsymbol{r})$ in the valence shell and the location of the active site has been established. ${ }^{[2,14,76]}$

\section{Acknowledgement}

The authors thank the National Science Council of the Republic of China for the financial support and are grateful to the National Center of HighPerformance Computing for access to their computing facilities and software packages.

[1] a) C. F. Mellot, A. M. Davidson, J. Eckert, A. K. Cheethan, J. Phys Chem. B 1998, 102, 2530-2535; b) S. E. Barber, K. E. S. Dean, A. J. Kirby, Can. J. Chem. 1999, 77, $792-801$; c) C. Cox, T. Lectka, J. Am. Chem. Soc. 1998, 120, 10660-11668; d) K.-J. Lin, Y. Wang, J. Phys. Chem. 1994, 98, $11685-11693$; e) A. Ivancich, T. A. Mattioli, Photosynth. Res. 1998, 55, 207-215; f) A. Aurora, G. D. Rose, Protein Sci., 1998, 7, 21 -38; g) G. R. Desiraju, Crystal Engineering - The Design of Organic Solids, Elsevier, New York, 1989.

[2] R. F. W. Bader, Atoms in Molecules: a Quantum Theory, Clarendon Press, Oxford, 1990.

[3] M. T. Caroll, C. Chang, R. F. W. Bader, Mol. Phys. 1988, 63, 387- 405.

[4] M. T. Caroll, R. F. W. Bader, Mol. Phys. 1988, 65, 695-722.

[5] P. L. A. Popelier, R. F. W. Bader, Chem. Phys. Lett. 1992, 189, $542-$ 548.

[6] T.-H. Tang, D. M. Whitefield, S. P. Douglas, J. J. Krepinsky, I. G. Csizmadia, Can. J. Chem. 1992, 70, 2434-2448.

[7] D. M. Whitefield, T.-H. Tang, J. Am. Chem. Soc. 1993, 115, $9648-$ 9654.

[8] C. Gatti, V. R. Saunders, C. Roetti, J. Chem. Phys. 1994, 101, $10686-$ 10696.

[9] U. Koch, P. L. A. Popelier, J. Phys. Chem. 1995, 99, 9747-9754.

[10] T.-H. Tang, Y.-P. Cui, Can. J. Chem. 1996, 74, 1162-1170.

[11] J. A. Platts, S. T. Howard, J. Chem. Phys. 1996, 105, 4668-4674.

[12] J. A. Platts, S. T. Howard, B. R. F. Bracke, J. Am. Chem. Soc. 1996, 118, $2726-2733$.

[13] P. L. A. Popelier, J. Phys. Chem. 1998, A102, 1873-1878.

[14] C. Gatti, R. Bianchi, R. Destro, F. Merati, J. Mol. Struct.(THEOCHEM) 1992, 255, 409-433.

[15] T. S. Koritsanszky, P. Coppens, Chem. Rev. 2001, 101, 1583-1627.

[16] P. Coppens, X-ray Charge Densities and Chemical Bonding, Oxford University Press, Oxford, 1997.

[17] P. Coppens, Acta Crystallogr. Sect. A 1998, 54, 779-788.

[18] R. Flaig, T. Koritsánszky, D. Zobel, P. Luger, J. Am. Chem. Soc. 1998, $120,2227-2238$.

[19] E. Espinosa, E. Molins, C. Lecomte, Chem. Phys. Lett. 1998, 285, $170-$ 173.

[20] J. Overgaad, B. Schiøtt, F. K. Larsen, A. J. Schultz, J. C. MacDonald, B. B. Iversen, Angew. Chem. 1999, 111, 1321-1324; Angew. Chem. Int. Ed. 1999, 38, 1239-1242.

[21] P. Coppens, Y. A. Abramov, M. Carducci, B. Korjov, I. Novozhilova, C. Alhambra, M. R. Pressprich, J. Am. Chem. Soc. 1999, 121, $2585-$ 2593.

[22] R. Flaig, T. Koritsánszky, J. Janczak, H.-G. Krane, W. Morgenroth, P. Luger, Angew. Chem. 1999, 111, 1494-1497; Angew. Chem. Int. Ed. 1999, 38, 1397-1400.

[23] F. Benabicha, V. Pichon-Pesme, C. Jelsch, C. Lecomte, A. Khmou, Acta Crystallogr. Sect. B 2000, 56, 155-165. 
[24] W. D. Arnold, L. K. Sanders, M. T. McMahon, A. V. Volkov, G. Wu, P. Coppens, S. R. Wilson, N. Godbout, R. Oldfield, J. Am. Chem. Soc. 2000, 122, 4708-4717.

[25] H.-P. Weber, B. M. Craven, Acta Crystallogr. Sect. B 1987, 43, $202-$ 209.

[26] R. F. W. Bader, Chem. Rev. 1991, 91, 893-928.

[27] E. Kraka, D. Cremer in The Concept of the Chemical Bond, Theoretical Models of Chemical Bonding, Part 2 (Ed.: Z. B. Makic), Springer-Verlag, New York, 1990.

[28] R. F. W. Bader, J. Phys. Chem. 1998, A102, 7314-7323.

[29] C.-R. Lee, T.-H. Tang, C.-C. Wang, L. Chen, Y. Wang, unpublished results.

[30] C.-R. Lee, L. Y. Tan, Y. Wang, J. Phys. Chem. of Solids, 2001, 62, $1613-1628$

[31] C.-C. Wang, T.-H. Tang, Y. Wang, J. Phys. Chem. 2000, A104, $9566-$ 9572.

[32] C.-R. Lee, C.-C. Wang, K.-C. Chen, G.-H. Lee, Y. Wang, J. Phys. Chem. 1999, A103, 156-165.

[33] V. G. Tsirelson, P.-F. Zou, T.-H. Tang, R. F. W. Bader, Acta Crystallogr. Sect. A 1995, 51, 143-153.

[34] T.-H. Tang, R. F. W. Bader, P. J. MacDougall, Inorg. Chem. 1985, 24, 2047-2053

[35] W. Scherer, M. Spiegler, B. Pedersen, M. Tafiposky, W. Hieringer, B. Reinhard, A. J. Downs, G. S. McGrady, Chem. Commun. 2000, 635.

[36] R. G. A. Bone, R. F. W. Bader, J. Phys. Chem. 1996, 100, $10892-$ 10911.

[37] a) Y. Aray, R. F. W. Bader, Surf. Sci. 1996, 351, 233-249; b) Y. Aray, J. Rodriguez, D. Vega, J. Phys. Chem. 2000, B104, 5225-5231.

[38] A. Gobbi, G. Frenking, J. Am. Chem. Soc. 1993, 115, 2362-2372.

[39] A. Masunov, J. J. Dannenberg, J. Phys. Chem. 1999, A103, 178-184; A. Masunov, J. J. Dannenberg, J. Phys. Chem. 2000, B104, 806-810.

[40] R. Dovesi, M. Causá, R. Orlando, C. Roetti, V. R. Saunders, J. Chem. Phys. 1990, 92, 7402-7411.

[41] S. Swaminathan, B. M. Craven, R. K. McMullan, Acta. Crystallogr. Sect. B 1984, 40, 300-306.

[42] K. Suzuki, S. Onishi, T. Koide, S. Seki, Bull. Chem. Soc. Jpn. 1956, 29, $127-131$.

[43] a) V. Zavodnik, A. Stash, V. Tsirelson, R. de Vries, D. Feil, Acta Crystallogr. Sect. B 1999, 55, 45-54; b) K. Y. Suponitsky, V. G. Tsirelson, D. Feil, Acta Crystallogr. Sect. A 1999, 55, 821-827; c) R. Y. de Vries, D. Feil, V. G. Tsirelson, Acta Crystallogr. Sect. B 2000, 56, 118-123.

[44] H. G. M. De Wit, J. C. Van Miltenburg, C. G. De Kruif, J. Thermodyn. 1983, $15,651-654$.

[45] I.-C. Chen, Y. Wang, Acta Crystallogr. Sect. C 1984, 40, 1937-1938.

[46] Y. Wang, N.-L. Chang, C.-T. Pai, Inorg. Chem. 1990, 29, 3256-3259.

[47] A. Volkov, C. Gatti, Y. Abramov, P. Coppens, Acta Crystallogr. Sect. A 2000, 56, 252-258.

[48] T.-S. Hwang, Y. Wang, J. Phys. Chem. 1998, A102, 3726-3731.

[49] J. Cioslowski, P. R. Surján, J. Mol. Struct.(THEOCHEM) 1992, 255, 9-33.

[50] A. E. Reed, P. v. R. Schleyer, J. Am. Chem. Soc. 1990, 112, 1434-1445.

[51] J. A. Dobado, H. Martinez-Garcia, J. M. Molina, M. R. Sundberg, J. Am. Chem. Soc. 1998, 120, 8461-8471; J. A. Dobado, H. MartinezGarcia, J. M. Molina, M. R. Sundberg, J. Am. Chem. Soc. 1999, 121, 3156-3164.

[52] A. Volkov, Y. Abramov, P. Coppens, C. Gatti, Acta Crystallogr. Sect. A 2000, 56, $332-339$.

[53] E. Espinosa, C. Lecomte, E. Molins, Chem. Phys. Lett. 1999, 300, 745 748.

[54] Y. A. Abramov, Acta Crystallogr. Sect. A 1997, 53, 264-272.
[55] E. Espinosa, I. Alkorta, I. Rozas, J. Elguero, E. Molins, Chem. Phys. Lett. 2001, 336, $457-461$.

[56] S. T. Howard, M. B. Hursthouse, C. W. Lehmann, P. R. Mallinson, C. S. Frampton, J. Chem. Phys. 1992, 97, 5616-5630.

[57] Y. A. Abramov, A. V. Volkov, P. Coppens, Chem. Phys. Lett. 1999, 311, $81-86$.

[58] T. Koritsánszky, S. Howard, T. Richter, Z. Su, P. R. Mallinson, N. K. Hansen, $X D$ (Computer Program Package for Multipole Refinement and Analysis of Electron Densities from X-ray Diffraction Data), Free University of Berlin, Germany, 1996.

[59] N. H. Hansen, P. Coppens, Acta Crystallogr. Sect. A 1978, 34, 909-921.

[60] N-H bond length $\approx 1.03 \AA$ A; see: F. H. Allen, Acta Crystallogr. Sect. B 1986, 42, 515-522.

[61] M, Souhassou, R. H. Blessing, J. Appl. Crystallogr. 1999, 32, 210-217.

[62] a) P. Hohenberg, W. Kohn, Phys. Rev. 1964, 136(B), B864-871; b) W. Kohn, S. J. Sham, Phys. Rev. 1965, 140(A), A1133-1138; c) R. G. Parr, W. Yang, Density-Functional Theory of Atoms and Molecules, Oxford University Press, Oxford, 1989.

[63] M. J. Frisch, G. W. Trucks, H. B. Schlegel, G. E. Scuseria, M. A. Robb, J. R. Cheeseman, V. G. Zakrzewski, J. A. Montgomery, R. E. Stratmann, J. C. Burant, S. Dapprich, J. M. Millam, A. D. Daniels, K. N. Kudin, M. C. Strain, O. Farkas, J. Tomasi, V. Barone, M. Cossi, R. Cammi, B. Mennucci, C. Pomelli, C. Adamo, S. Clifford, J. Ochterski, G. A. Petersson, P. Y. Ayala, Q. Cui, K. Morokuma, D. K. Malick, A. D. Rabuck, K. Raghavachari, J. B. Foresman, J. Cioslowski, J. V. Ortiz, B. B. Stefanov, G. Liu, A. Liashenko, P. Piskorz, I. Komaromi, R. Gomperts, R. L. Martin, D. J. Fox, T. Keith, M. A. Al-Laham, C. Y. Peng, A. Nanayakkara, C. Gonzalez, M. Challacombe, P. M. W. Gill, B. G. Johnson, W. Chen, M. W. Wong, J. L. Andres, M. Head-Gordon, E. S. Replogle, J. A. Pople, Gaussian 98 (Revision A.7), Gaussian Inc., Pittsburgh, PA, 1998.

[64] C. Lee, W. Yang, R. G. Parr, Phys. Rev. B. 1988, 37(2), 785-789.

[65] A. D. Becke, J. Chem. Phys. 1993, 98, 5648-5652.

[66] M. M. Francl, W. J. Pietro, W. J. Hehre, J. S. Binkley, M. S. Gordon, D. J. DeFrees, J. A. Pople, J. Chem. Phys. 1982, 77, 3654-3665.

[67] V. R. Saunders, R. Dovesi, C. Roetti, M. Causá, N. M. Harrison, R. Orlando, C. M. Zicovich-Wilson, CRYSTAL 98 User's Manual, University of Torino, Italy, 1998.

[68] R. F. W. Bader, F. W. Biegler-König, J. R. Cheeseman, J. A. Duke, T. A. Keith, P. Krug, K. E. Laidig, B. Langdon, AIMPAC (a set of programs for the theory of atoms in molecules), McMaster University, Hamilton, ON, Canada, 1994.

[69] D.-C. Fang, T.-H. Tang, AIM98PC (modified PC version of AIMPAC), 1998.

[70] C. Gatti, TOPOND98 User's Manual 1998, CNR-CSRSRC, Milano, Italy.

[71] R. F. W. Bader, T.-H. Tang, Y. Tal, F. W. Biegler-König, J. Am. Chem. Soc. 1982, 104, $946-952$.

[72] a) R. F. W. Bader, T. Slee, D. Cremer, E. Kraka, J. Am. Chem. Soc. 1983, 105, 5061 -5068; b) S. M. Bachrach, J. Comput. Chem. 1989, 10, $392-406$; c) S. M. Bachrach, J. Mol. Struct.(THEOCHEM) 1992, 255, 207-219; d) S. M. Bachrach, J. Mol. Struct.(THEOCHEM) 1995, 337, $201-207$.

[73] D. Cremer, E. Kraka, Croatica Chem. Acta 1984, 57, 1259-1281.

[74] S. Grimme, J. Am. Chem. Soc. 1996, 118, 1529-1534.

[75] F. W. Biegler-König, R. F. W. Bader, T.-H. Tang, J. Comp. Chem. 1982, 3, 317-328.

[76] R. F. W. Bader, P. L. A. Popelier, C. Chang, J. Mol. Struct.(THEOCHEM) 1992, 255, 145-17.

Received: October 21, 2002 Revised version: March 6, 2003 [F 4519] 